\title{
A cathepsin L-like protease from Strongylus vulgaris: An orthologue of Caenorhabditis elegans CPL-1 is
}

\author{
Sinéad Nic An Ultaigh ${ }^{\mathrm{a}}$, James C. Carolan ${ }^{\mathrm{a}}$, Collette Britton ${ }^{\mathrm{b}}$, Linda Murray ${ }^{\mathrm{b}}$, Michael F. Ryan ${ }^{\mathrm{a}, \mathrm{c}, *}$ \\ a School of Biology and Environmental Science, University College Dublin, Belfield, Dublin 4, Ireland \\ ${ }^{\mathrm{b}}$ Division of Veterinary Infection and Immunity, University of Glasgow Veterinary School, Bearsden Road, Glasgow G61 1QH, Scotland, UK

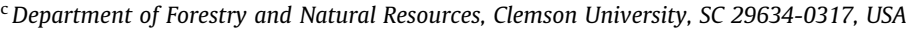

\section{A R T I C L E I N F O}

\section{Article history:}

Received 19 September 2008

Accepted 3 November 2008

Available online 18 November 2008

\section{Keywords:}

Nematode

Equine parasite

Strongylus vulgaris

Cathepsin L gene

C. elegans mutant rescue

\begin{abstract}
A B S T R A C T
Cathespin L-like proteases (CPLs), characterized from a wide range of helminths, are significant in helminth biology. For example, in Caenorhabditis elegans CPL is essential for embryogenesis. Here, we report a cathepsin L-like gene from three species of strongyles that parasitize the horse, and describe the isolation of a $\mathrm{cpl}$ gene (Sv-cpl-1) from Strongylus vulgaris, the first such from equine strongyles. It encodes a protein of 354 amino acids with high similarity to other parasitic Strongylida (90-91\%), and C. elegans CPL-1 (87\%), a member of the same Clade. As S. vulgaris cpl-1 rescued the embryonic lethal phenotype of the C. elegans cpl-1 mutant, these genes may be orthologues, sharing the same function in each species. Targeting Sv-CPL-1 might enable novel control strategies by decreasing parasite development and transmission.
\end{abstract}

(c) 2008 Elsevier Inc. All rights reserved.

\section{Introduction}

Nematode parasites of the horse include more than 50 species of Strongylida from the subfamilies Strongylinae (large strongyles) and Cyathostominae (small strongyles). Strongylus vulgaris is the most pathogenic of the large strongyles, the migrating larval stages causing verminous arteritis and thrombosis, and adult stages anemia and poor performance. The use of modern anthelmintics has decreased the prevalence of $S$. vulgaris but has increased anthelmintic resistance and prevalence of cyathostomes (Kaplan, 2002). Indeed, multiresistant cyathostomes (to all three types of anthelmintics used to control equine nematodes) has recently been reported in Brazil (Molento et al., 2008). Clearly, alternative control strategies and/or novel candidates for vaccines against equine strongyles are required. S. vulgaris is the most pathogenic and most widely studied species, and novel control strategies for it might apply to other species of equine strongyles.

As parasite proteases, especially cathepsins, affect a broad range of biological processes including nutrition, digestion, blood coagulation, host immune invasion and tissue penetration (Tort et al.,

Abbreviations: CPL, cathepsin L; GFP, green fluorescent protein.

Note: Nucleotide sequence data presented here is available in the GenBank ${ }^{\mathrm{TM}}$ database under the accession numbers EU000410, EU000411, EU884414 and EU884415.

* Corresponding author. Address: School of Biology and Environmental Science, University College Dublin, Belfield, Dublin 4, Ireland. Fax: +353 17161152.

E-mail address: mfryan@ucd.ie (M.F. Ryan).
1999), they are appropriate targets for chemotherapy and vaccines (McKerrow, 1999; Sajid and McKerrow, 2002). Cathepsin B-like protease genes, a large multigene family in both free-living and parasitic nematodes, are expressed in the intestine of Haemonchus contortus and Caenorhabditis elegans and may enable nutrient digestion (Ray and McKerrow, 1992; Larminie and Johnstone, 1996; Jasmer et al., 2001). Cathepsin L- and Z-like proteases are associated with larval moulting in parasitic nematodes and may have multifunctional roles in worm development (Guiliano et al., 2004; Lustigman et al., 2004). A cathepsin Z-like protease has a multifunctional role in development, and a cathepsin L-like (CPL) protease is essential for early embryogenesis, in C. elegans (Hashmi et al., 2002, 2004).

As recent molecular phylogenetic studies have placed $C$. elegans and the Strongylida in the same Clade (Blaxter et al., 1998; Holterman et al., 2006), C. elegans is an appropriate model organism for these parasites (Blaxter et al., 1998; Brooks and Isaac, 2002). The ability of an $H$. contortus cathepsin L-like gene to functionally rescue a C. elegans cpl-1 mutant phenotype suggests that the parasite $c p l$ may be an orthologue of C. elegans cpl-1 (Britton and Murray, 2002).

As cathepsin L-like activity predominates in S. vulgaris excretory-secretory products (Caffrey and Ryan, 1994), we now report the isolation of a $\mathrm{cpl}$ gene from $\mathrm{S}$. vulgaris and demonstrate that it rescues the $C$. elegans $\mathrm{cpl}-1$ genetic mutant phenotype. This is the first $S$. vulgaris gene to be characterized at genomic and functional levels and it indicates conservation of cathepsin L gene function in Strongylida. 


\section{Materials and methods}

\subsection{Nematode material}

Strongylus vulgaris adults removed from the caecum of freshly slaughtered horses (Caffrey and Ryan, 1994) were stored in RNA later (Invitrogen). Strongylus edentatus and Cyathostominum catinatum specimens were available from previous studies in the laboratory. C. elegans strains used in this study were either wild type N2 Bristol strain, or C. elegans genetic mutant (allele ok360) from the $C$. elegans Gene Knockout Consortium, maintained as a homozygous mutant, and rescued with C. elegans cpl-1 (Britton and Murray, 2004). Both strains were cultured as described previously (Epstein and Shakes, 1995).

\subsection{Isolation of genomic cpl gene fragments}

Genomic DNA (gDNA) was extracted from single adult $S$. vulgaris using DNeasy Extraction Kit (Qiagen). Nested degenerative PCR was carried out on gDNA using the degenerate forward primers cpl-DF1, (5'-GGIATGTG[T/C]GGITCITG[T/C]TGGGGC-3') and cplDF2 (5'-GA[A/G]CA[A/G]AA[T/C]CTGT IGA[T/C]TG-3') in combination with the degenerate reverse primer cpl-DR1 (5'-AIGC[T/C] $\mathrm{TC}[\mathrm{T} / \mathrm{C}] \mathrm{TC}[\mathrm{A} / \mathrm{G}] \mathrm{TCICC}[\mathrm{T} / \mathrm{C}] \mathrm{TCIGG}-3^{\prime}$ ). The amino acid sequence encoded by these primers is highly conserved in nematode CPL genes (Britton and Murray, 2004). PCR was performed in $25 \mu$ l volumes using $1 \mu \mathrm{l}$ template, $0.8 \mu \mathrm{M}$ each degenerate primers cpl-DF1 and cpl-DR1, and the following thermocycling parameters: $94{ }^{\circ} \mathrm{C}$ for $3 \mathrm{~min}, 30$ cycles of $\left(94^{\circ} \mathrm{C}\right.$ for $1 \mathrm{~min}, 45^{\circ} \mathrm{C}$ for $1 \mathrm{~min}, 72^{\circ} \mathrm{C}$ for $1 \mathrm{~min}$ ), with a final extension of $72^{\circ} \mathrm{C}$ for $7 \mathrm{~min}$. After cleaning by a Novagen PCR clean-up kit, $1 \mu$ of this PCR product served as a template in the 2 nd round nested PCR. Conditions were as for the 1 st round except for an annealing temperature of $48^{\circ} \mathrm{C}$, and use of primers cpl-DF2 and cpl-DR1, both at $0.8 \mu \mathrm{M}$.

Cleaned amplified fragments were sequenced (Macrogen, Korea). As the genomic segment had greatest identity with other nematode cathepsin L-like genes (BLAST; http://www.ncbi. nlm.nih.gov/blast/), internal gene specific primers SvF1 (5'-TCATG GAATTGACACTGAAG-3') and SvR1 (5'-GTCCTCGGCACCGATATC-3') were designed for use with cDNA.

Isolation of genomic DNA fragments from $S$. edentatus and $C$. catinatum was carried out as detailed above.

\subsection{RNA isolation and cpl cDNA cloning}

Total RNA was isolated from individual S. vulgaris adults by homogenisation in TRIzol (Invitrogen). Approximately $4 \mu \mathrm{g}$ RNA was treated with DNAse (Invitrogen) prior to single strand cDNA synthesis using oligo $\mathrm{d}(\mathrm{T})$ primer and Superscript II reverse transcriptase (Invitrogen). One microlitre of the resulting cDNA served as template in subsequent PCRs. The $3^{\prime}$ end of the $S v-c p l-1$ gene was obtained using SvF1 and oligo $\mathrm{d}(\mathrm{T})$ primers $(0.4 \mu \mathrm{M})$, at the same reagent concentrations as described above, and the following PCR cycling conditions; $94^{\circ} \mathrm{C}$ for $1 \mathrm{~min}, 50^{\circ} \mathrm{C}$ for $1 \mathrm{~min}$ and $72{ }^{\circ} \mathrm{C}$ for $1 \mathrm{~min}, 30$ cycles. The $5^{\prime}$ end of the $S v$-cpl-1 gene was determined using internal gene specific reverse primer SvR1 and the nematode splice leader primer, SL1 (5'-GGTTTAATTACCCAAGTTTGAG-3') under permissive conditions (annealing temperature of $50{ }^{\circ} \mathrm{C}$ ). The less stringent nature of this PCR resulted in multiple fragments that resolved on a $1.8 \%$ agarose gel run for $1 \mathrm{hr}$ and were visualized briefly under UV light. Sterile syringe needles were used to transfer each fragment to a prepared PCR reaction mix containing the SL1 and SvR1 primers. Products of successful PCRs, represented by fragments of the same size as the initial PCR fragment, were gel-purified using the Wizard ${ }^{\circledR}$ Sv Gel and PCR clean-up kit (Promega) and were cloned into PCR2.1 TOPO Vector (Invitrogen). One shot $E$. coli cells (Invitrogen) were transformed with product, and miniprep plasmid DNA (Spin Miniprep kit, Qiagen) from positive colonies was sequenced (Macrogen) using vector specific M13 forward and reverse primers.

Gene specific primers, designed to amplify the entire $S v$-cpl-1 cDNA gene, contained restriction sites to facilitate directional cloning into PCR2.1 TOPO expression vector and had the following sequences; SvF2 (5'-GAGTCTAGAATGTTCCGGCTGTTATC-3'), and SvR3 (5'-ATCAGTCGACTTCAAACAAGTGGGTAAC-3') (the underline indicates Sall and $\mathrm{XbaI}$ sites, respectively, start and stop codons are in italics). PCR cycling conditions were as above except for an annealing temperature of $50{ }^{\circ} \mathrm{C}$. The resulting PCR products were sequenced to confirm correct DNA sequence.

\subsection{Isolation of the genomic Sv-cpl-1 sequence}

The $S v$-cpl-1 genomic sequence was ascertained using a primer walking strategy as primers designed from cDNA sequence repeatedly gave PCR products much shorter than expected (data not shown). Accordingly, primers were designed with a 4 or $5 \mathrm{bp}$ intron anchor where possible (Table 1). This strategy is illustrated in Fig. 1. Bands were gel-purified, cloned into a PCR2.1 TOPO vector and sequenced. PCR reagent concentrations and cycling parameters were as described previously.

\subsection{Sequence and phylogenetic analysis}

Forward and reverse sequence reads were assembled using Sequencher $^{\text {TM }}$ Version 3.1 (Gene Codes Corporation, 1999). Homology searches with the full Sv-cpl-1 cDNA sequence were performed using BLAST, and CPL amino acid sequences for a number of species were aligned using CLUSTAL W (http://www.ebi.ac.uk/clustatlW/). Putative signal peptide cleavage sites were identified using Signal $\mathrm{P}$ (Nielsen et al., 1997) at www.expasy.org/tools/signalP and TargetP (Emanuelsson et al., 2000) at www.expasy.org/tools/targetP. Percentage similarity was determined using mean character differences calculated in PAUP (Swofford, 2002).

\subsection{Generation of the S. vulgaris cpl-1 rescue clone}

A construct containing the $S$. vulgaris $c p l-1$ cDNA was generated using restriction digest and cloning steps (Britton and Murray,

Table 1

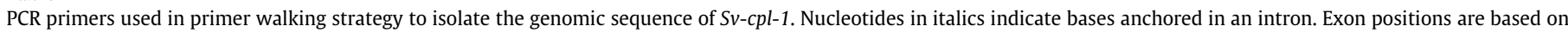
the cDNA sequence.

\begin{tabular}{|c|c|c|c|}
\hline & Primer combination & Forward $(\mathrm{F})$ primers and positions & Reverse (R) primers and positions \\
\hline $5^{\prime}$ end & $\begin{array}{l}\text { SvF3 and SvR5 } \\
\text { SvF3 and SvR7 } \\
\text { SvF4 and SvR1 }\end{array}$ & $\begin{array}{l}\text { 5'-CAATGTTCCGGCTGTTATC-3'-2 - } 17 \text { cDNA } \\
\text { 5'-CAATGTTCCGGCTGTTATC-3'-2 - } 17 \text { cDNA } \\
\text { 5'-ACTTTTGAGATGGGATTG-3'Exon } 3\end{array}$ & $\begin{array}{l}\text { 5'-CTTACAAGATCAGCAATGCTG-3'Intron 3/exon } 3 \\
\text { 5'-CTTACCAAAGGACTCCTTG-3'Intron 2/exon } 2 \\
5^{\prime} \text {-GTCCTCGGCACCGATATC-3'Exon } 7\end{array}$ \\
\hline $3^{\prime}$ end & $\begin{array}{l}\text { SvF5 and SvR4 } \\
\text { SvF5 and SvR8 }\end{array}$ & $\begin{array}{l}\text { 5'-CAT TTATCCTTTCAGGAGAC -3'Intron 6/exon } 7 \\
5^{\prime} \text {-CATTTATCCTTTCAGGAGAC-3'Intron 6/exon } 7\end{array}$ & $\begin{array}{l}\text { 5'-CAAACAAGTGGGTAACTG-3'1098-1130 cDNA } \\
\text { 5'-GACTTACCTGTTCTTGATTAG-3'Intron 9/exon } 9\end{array}$ \\
\hline
\end{tabular}




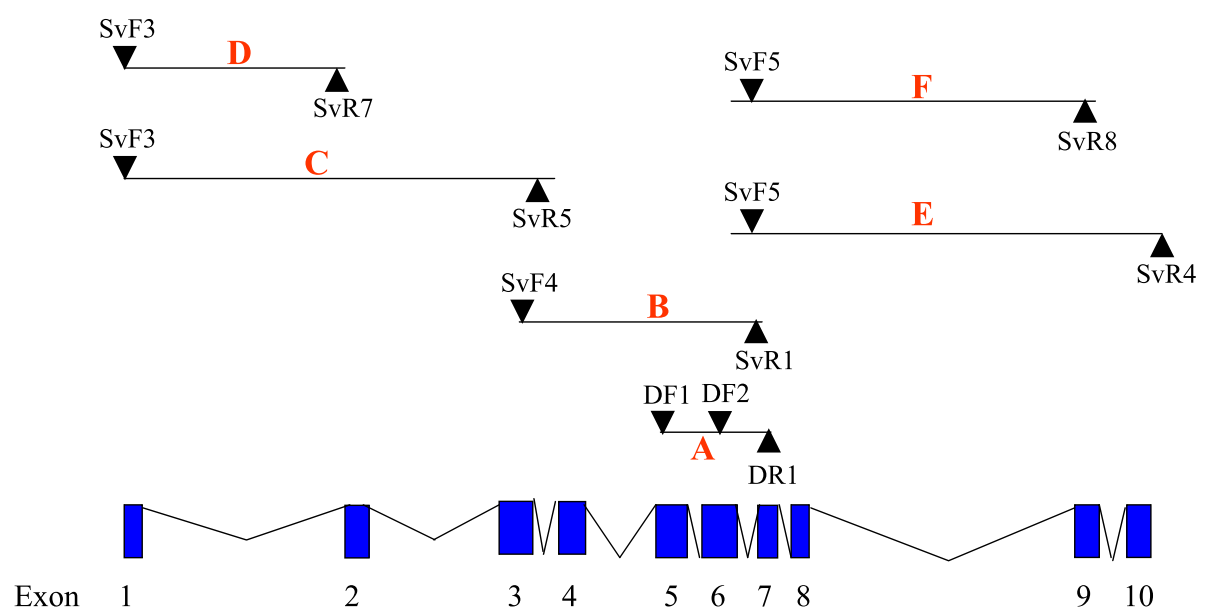

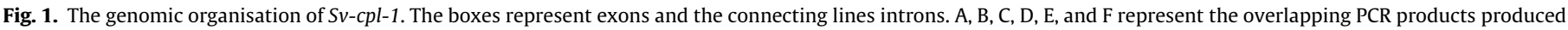
using the primer walking strategy. Primer details are in Table 1.

2002). The starting construct contained $1.76 \mathrm{~Kb}$ of $\mathrm{Ce}$-cpl-1 upstream sequence, cDNA coding sequence of the C. elegans cpl-1 gene, and $512 \mathrm{bp} \mathrm{Ce-cpl-1} 3^{\prime}$ untranslated region. This construct was digested with Sall and Xbal restriction enzymes to remove the $C e-c p l-1$ cDNA sequence. The resulting fragment containing the $1.76 \mathrm{~kb}$ of $\mathrm{Ce}-\mathrm{cpl}-1$ upstream sequence and the $3^{\prime}$ untranslated region was gel-purified and ligated overnight with the $S v$-cpl-1 coding sequence, which had also been digested with Sall and XbaI restriction enzymes and gel-purified. The resulting product was transformed into E. coli X1 cells by standard methods. Selected clones were screened by direct colony PCR using gene specific primers SvF2 and SvR3. Plasmid DNA from positive colonies was purified using the Spin Miniprep Plasmid kit (Qiagen) and an additional ethanol precipitation step. Insert DNA was sequenced to confirm replacement of the Ce-cpl-1 cDNA with Sv-cpl-1 cDNA (MWG, Germany).

\subsection{Transformation and rescue of $\mathrm{Ce}$-cpl-1 genetic mutant}

The C. elegans cpl-1 genetic mutant strain used for rescue studies was maintained as a homozygous mutant rescued with the $\mathrm{Ce}$ cpl-1 cDNA together with dpy-7: GFP as a transformation marker (Britton and Murray, 2004). Homozygous Ce-cpl-1 mutant hermaphrodites produce $95-100 \%$ dead embryos and cannot be maintained. The Ce-cpl-1 transgene was maintained as an extrachromosomal array, with around $70 \%$ of worms in each generation carrying the transgene. The $S v-c p l-1$ rescue construct (described above) was microinjected with $C$. elegans marker gene rol-6 (at final concentrations of $25 \mathrm{ng} / \mu \mathrm{l}$ and $100 \mathrm{ng} / \mu \mathrm{l}$, respectively) into the distal arm of Ce-cpl-1/dpy-7: GFP hermaphrodites using a standard procedure (Mello et al., 1991). Transformed worms, exhibiting the roller phenotype and loss of the GFP marker gene, were maintained as discrete lines.

To verify that transformants expressing the rol-6 phenotype (rollers) contained the Sv-cpl-1 construct and had lost the Ce-cpl1 array, single worm PCR was carried out. Briefly, single adult rollers were picked into $4 \mu \mathrm{l}$ of lysis buffer ( $50 \mathrm{mM} \mathrm{KCl}, 10 \mathrm{mM}$ Tris$\mathrm{HCl}, \mathrm{pH} 8.3,2.5 \mathrm{mM} \mathrm{MgCl} 2,0.45 \%$ Nonidet P-40, 0.45\% Tween 20, $0.01 \%$ gelatin, freshly added $60 \mu \mathrm{g} / \mathrm{ml}$ proteinase $\mathrm{K}$ ), incubated at $-70{ }^{\circ} \mathrm{C}$ for $10 \mathrm{~min}$, at $60^{\circ} \mathrm{C}$ for $1 \mathrm{~h}$, followed by $95^{\circ} \mathrm{C}$ for $15 \mathrm{~min}$ to inactivate proteinase K. PCR was carried out using $S$. vulgaris gene specific primers, SvF2 and SvR3, with all of the lysate as template. PCR cycling conditions were as detailed above. Control PCRs were carried out with non-roller adults from each transformed line and N2 Bristol wild type strain. C. elegans $\mathrm{cpl}-1$ specific primers
(Britton and Murray, 2004) were used to confirm the presence of the mutant $C e-c p l-1$ gene within the genome and loss of the wild type $C e-c p l-1$ extrachromosomal array.

\subsection{Immunoblotting}

The expression of Sv-CPL-1 only in transformed lines was confirmed by immunoblotting. Approximately 75 adult rollers, transferred to eppendorf tubes and washed in PBS, were centrifuged and most of the supernatant was removed except for approximately $20 \mu$ l. SDS-loading buffer $(4 \times$ concentration; 5\% SDS, $1 \mathrm{M}$ Tris- $\mathrm{HCl} \mathrm{pH} 7.5,80 \%$ glycerol, $0.1 \%$ Bromophenol blue) was added and the worms were frozen overnight at $-20^{\circ} \mathrm{C}$. Samples were incubated with $5 \%$ mercaptoethanol, boiled at $95^{\circ} \mathrm{C}$ for $10 \mathrm{~min}$, and centrifuged at $13,000 \mathrm{rpm}$ for $5 \mathrm{~min}$. Extracts were then resolved on $12.5 \%$ acrylamide gels using the Atto Corporation minislab system, and transferred onto a PVDF membrane that was immersed for $1 \mathrm{~h}$ in blocking solution (BS, Tris-buffered saline (TBS), $\mathrm{pH} 7.4$, with $5 \%$ Marvel, non-fat dried milk). The membrane was incubated overnight at $4{ }^{\circ} \mathrm{C}$ in BS containing antibody against the mature region of $C$. elegans CPL-1 (diluted 1:300) (Britton and Murray, 2004). After washing in TBST (Tris-buffered saline containing $0.1 \%$ Tween 20), $6 \times 5 \mathrm{~min}$, membranes were incubated for $1 \mathrm{~h}$ with HRP-conjugated anti-rabbit IgG (Pierce), diluted 1:1500 in BS. They were then washed, incubated in SuperSignal ${ }^{\circledR}$ West Pico Chemiluminescent substrate (Pierce), and developed using Kodak ${ }^{\circledR}$ BioMax light film. Non-rollers and pre-immune serum served as controls.

\section{Results and discussion}

\subsection{Isolation and characterisation of cathepsin L-like cDNA}

An initial genomic fragment (approximately $280 \mathrm{bp}$ ) amplified from adult $S$. vulgaris served in the design of two internal gene specific primers. These were used in conjunction with either the nematode splice leader SL-1 or Oligo $\mathrm{d}(\mathrm{T})$ primers to amplify the complete cDNA sequence in two overlapping cDNA fragments. Gene specific primers, designed to the putative start and stop codons, amplified the entire coding sequence of the $S$. vulgaris cathepsin L cDNA (designated Sv-cpl-1), which was identical to the sequence assembled from the $5^{\prime}$ and $3^{\prime}$ fragments (Fig. 2).

Sv-cpl-1 encodes a protein of 354 amino acids with a predicted mass of $39,965 \mathrm{Da}$, and a calculated pI of 5.93, comprising a signal peptide, a pro-domain and a mature domain. The putative hydro- 


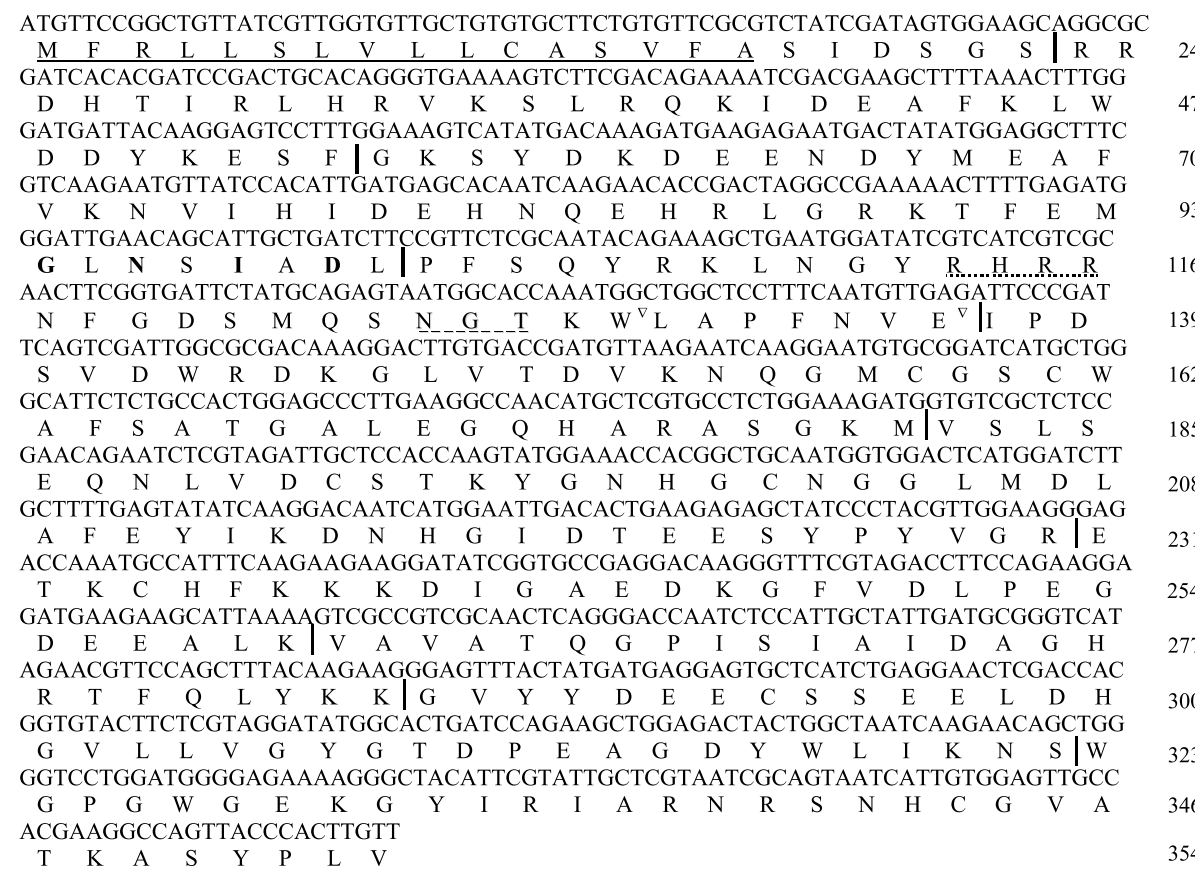

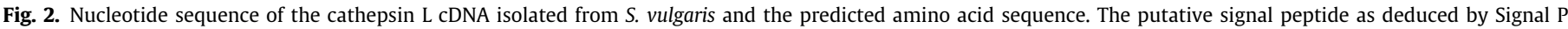

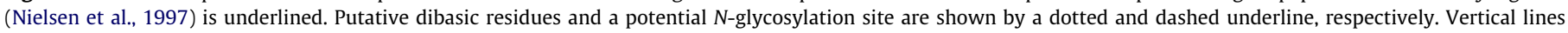

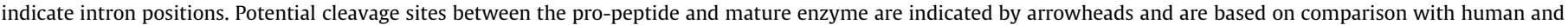
other nematode CPLs.

phobic signal peptide sequence has a predicted cleavage site between residues 16 and 17 (Ala-Ser).

Two putative cleavage sites between the pro-domain and the mature domain were identified as $\mathrm{Leu}^{130}$ and $\mathrm{Ala}^{131}$ and Glu ${ }^{136}$ and Ala $^{137}$, revealing pro-domains of 114 and 120 amino acid residues, respectively (Fig. 2). Dibasic residues are present approximately 14 amino acids $\mathrm{N}$-terminal to the first proposed prodomain cleavage site. A putative $\mathrm{N}$-glycosylation site is present in Sv-CPL-1 at position 124 (Fig. 2 numbering) just preceding the potential pro-domain cleavage sites. The ERFNIN motif, characteristic of non-cathepsin B papain-like proteases, occurs in the prodomain of Sv-CPL-1. The sequence motif GXNXFXD is highly conserved in Sv-CPL-1, although the Phe is replaced by Ile, as with other nematode CPLs. It occurs in proregions of cysteine proteases of the papain superfamily, and may serve intramolecular processing of papain (Vernet et al., 1995).

The predicted mature domain of 224 amino acids contains the catalytic triad cysteine, histidine and asparagine residues characteristic of cysteine proteases. The predicted amino acid sequence of the mature domain of Sv-CPL-1 had greatest homology to CPLs from Haemonchus contortus (91\%), Dictyocaulus viviparus (90\%), C. briggsae (88\%) and C. elegans (87\%) respectively of 20 nematode CPLs screened (Fig. 3A). Corresponding values for trematodes are Fasciola hepatica (48\%), Schistosoma japonicum (52\%), S. mansoni (56\%). Phylogenetic analysis showed that Sv-CPL-1 clustered with CPLs from the strongylids, H. contortus and D. viviparus (Fig. 3B).

\subsection{Characterisation of genomic sequence}

Obtaining the genomic sequence of $S v-c p l-1$ was problematical using primers designed from the cDNA coding sequence as they consistently amplified two bands; a larger band of expected size inclusive of introns and a smaller band of expected size without introns. Sequencing established the larger band as the $S v$-cpl-1 sequence inclusive of introns, whilst the smaller band had the same sequence as the cDNA.
As the first detailed genomic information on any protease gene from S. vulgaris, $S v$-cpl-1 contains 9 introns, the positions of which are conserved between $H$. contortus, $D$. viviparus and $S$. vulgaris. In the relatively small genomic fragment isolated from $S$. edentatus the position of introns 5 and 6 are similarly conserved. Intron size in S. vulgaris ranged from $50 \mathrm{bp}$ to $1083 \mathrm{bp}$, with intron 8, the largest intron, containing $1083 \mathrm{bp}$. All intron/exon boundaries conformed to the GT/AG rule (Breathnach and Chambon, 1981).

From a $c p l$ fragment of approximately $280 \mathrm{bp}$ amplified from $S$. edentatus gDNA, an internal gene specific reverse primer was designed and used in combination with cpl-DF1, which amplified a $c p l$ fragment of approximately $400 \mathrm{bp}$ containing two introns. Attempts to amplify any additional genomic sequence were unsuccessful.

A product $<300$ bp without introns was amplified from $C$. catinatum using $S$. vulgaris-specific reverse primer, SvR1, in combination with cpl-DF1. As with $S$. edentatus, subsequent PCRs failed to amplify additional sequence, and a primer walking strategy would be required to amplify the remaining sequence.

Although the presence of the cDNA copy in genomic DNA indicated possible RNA contamination in all of the above species, RNAse-treated DNA and the use of high quality proof-reading Taq produced similar results. This is consistent with the presence of a processed pseudogene (a possible retrotransposon) in $S$. vulgaris. Retropseudogenes occur in a range of animal and plant species (Harrison et al., 2001) and up to $20 \%$ of annotated genes in C. elegans may be pseudogenes (Mounsey et al., 2007).

\subsection{Rescue of C. elegans genetic mutants with S. vulgaris $\mathrm{cpl}-1$}

In the present study $C$. elegans homozygous $c p l-1$ mutant hermaphrodites were transformed with the $S v$-cpl-1 transgene, using rol- 6 as a co-transformation marker. Four discrete transgenic lines were established with a mixture of roller and non-roller worms in each line. The $C$. elegans genetic mutant phenotype is embryonically lethal and the $S v-c p l-1$ plasmid resulted in $99 \%$ rescue of 
A

G. pallida
$H$. glycines
R. reniformis
M. incognita
H. Contortus
D. Viviparus
S. vulgaris
C. elegans
Human

G. pallida

H. glycines

R. reniformis

M. incognita

$M$. incognita
$H$. contortus

H. Contortus

S. vulgaris

C. elegans

Human

G. pallida

H. glycines

$R$. reniformis

M. incognita

H. contortus

D. viviparus

S. vulgaris

Human

G. pallida

H. glycines

$R$. reniformis

M. incognita

H. Contortus

D. viviparu

C. vulgaris

C. catinatum

. edentatus

Human

G. pallida

H. glycines

R. reniformis

M. incognita

$H$. contortus

D. viviparus

S. viviparus

c. catinatum

- Catinatum

S. edentatus

Human

G. pallida

H. glycines

$R$. reniformis

M. incognita

$M$. incognita

$H$. Contortus

- viviparus

- vulgaris

C. elegans

Human

G. pallida

H. glycines

$R$. reniformis

$M$. incognita

$H$. contortus

D. viviparus

S. vulgaris

. vulgaris

Human
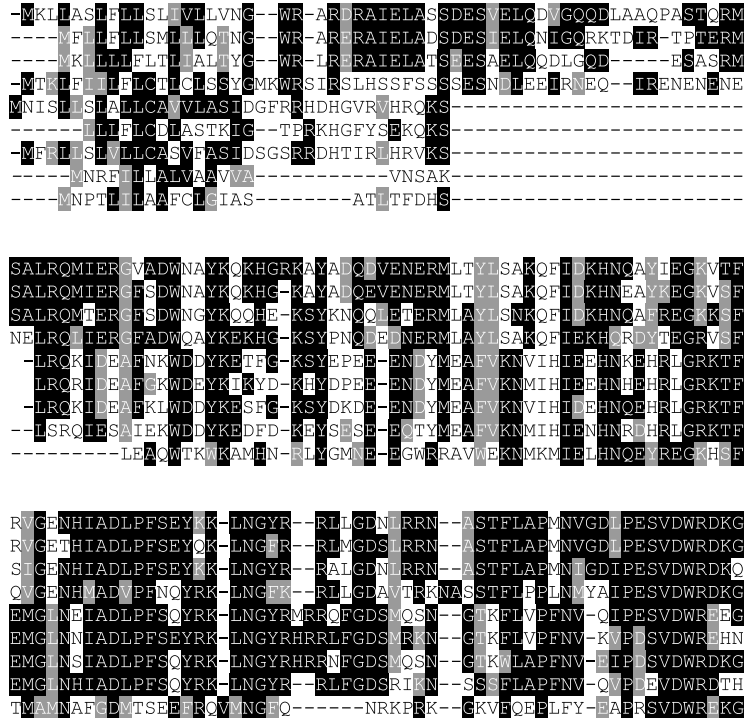

$\nabla$
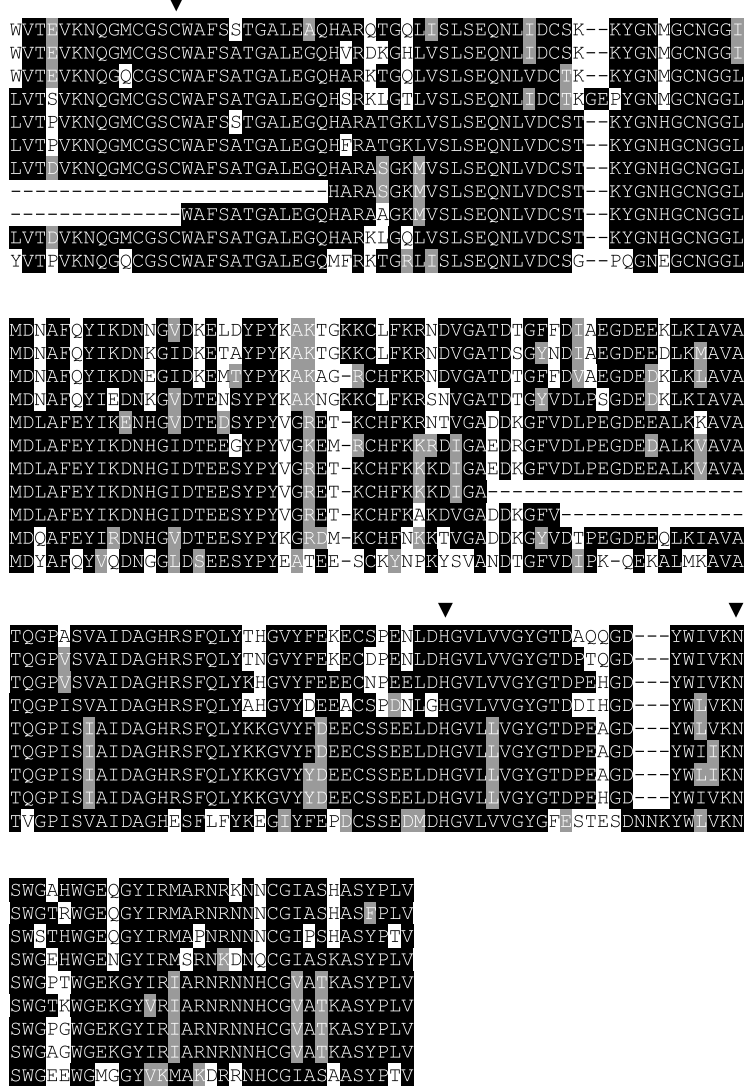

B

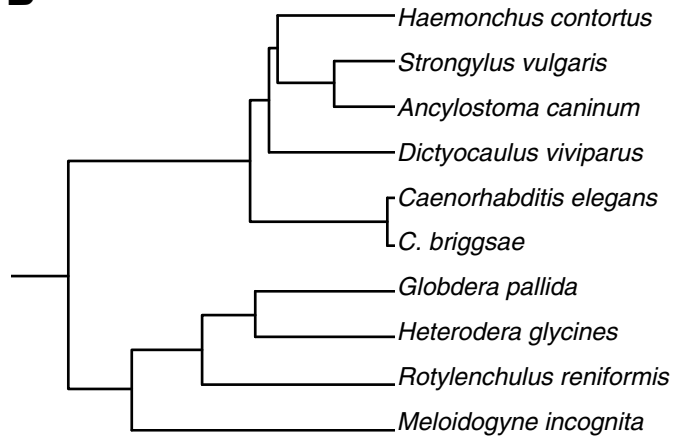

0.05 changes

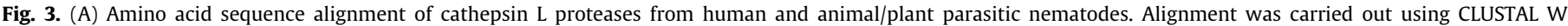

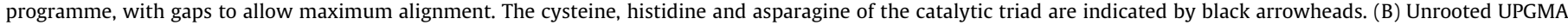

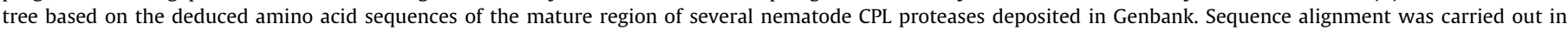

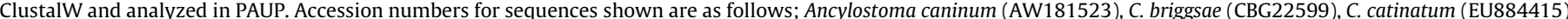

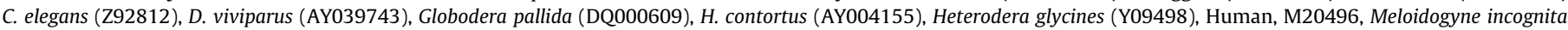
(AJ557572) Rotylenchulus reniformis (AY999066), S. edentatus (EU884414), S. vulgaris (EU000410).

the mutant phenotype. Non-roller worms, taken from each line, exhibited $100 \%$ embryonic lethality.

Sv-cpl-1 was confirmed in the transformed worms by single worm PCR on roller and non-roller worms using $S$. vulgaris gene specific primers SvF2 and SvR3. All rollers contained the S. vulgaris cDNA coding sequence whereas non-rollers and wild type N2 Bris- tol strain did not (Fig. 4A). Western blot analysis with anti-Ce-CPL confirmed expression of CPL-1 protein only in rescued roller worms (Fig. 4B). A band of approximately $42 \mathrm{kDa}$ was evident in all four established roller lines (only lines 1 and 2 are shown in Fig 4B). No band was evident in non-roller worms from each line. Pre-immune serum or only secondary antibody controls did not re- 
act with the detected band. These results are similar to that of another study where $H$. contortus $\mathrm{cpl}-1$ rescued the C. elelgans $\mathrm{cpl}-1$ genetic mutant phenotype (Britton and Murray, 2002).

A second band of approximately $41 \mathrm{kDa}$ was also intermittently detected and is most likely due to a post-modification event (such as glycosylation), or processing of the CPL protease. As activation of cathepsin $\mathrm{L}$ in both human and fluke is a multi-step process (Ishidoh et al., 1998; Collins et al., 2004), this band could represent another form of the mature enzyme; intermolecular processing of human cathepsin L entails cleavage at two positions (Ménard et al., 1998).

Cathepsin L gene families identified in Trematodes such as Schistosoma japonicum, S. mansoni, Fasciola hepatica and F. gigantica, enable feeding/digestion of host tissue (Smith et al., 1993; Day et al., 1995; Dowd et al., 1997; Yamasaki et al., 2002). Trematode CPLs may also suppress or modulate the host immune response (Dalton et al., 2003). A family of CPLs isolated from the filarial nematodes Brugia malayi and B. pahangi, are associated with larval moulting and multifunctional roles during development (Guiliano et al., 2004). RNA interference (RNAi) has revealed an essential role for cathepsin Land Z-like proteases in larval moulting in Onchocerca volvulus (Lustigman et al., 2004). Larvae exposed to cpl and cpz double-stranded RNA did not moult, suggesting that cathepsin L was involved in the digestion of old cuticle, degradation of cuticular anchoring proteins, or activation of other enzymes involved in moulting.

CPL proteases are associated with the digestive processes in $\mathrm{J} 2$ stages of the plant parasite Meloidogyne incognita and may influence the host-parasite relationship (Neveu et al., 2003). RNAi targeting of $M$. incognita cathepsin L ( $M i-c p l-1)$, decreased cysteine protease activity in $\mathrm{J} 2 \mathrm{~s}$, and decreased the number of egg-laying females (Shingles et al., 2007). In C. elegans, CPL-1 is essential for embryogenesis and is required for the correct processing of yolk proteins (Hashmi et al., 2002; Britton and Murray, 2004). A vaccine from $F$. hepatica cathepsin L proteases elicited significant protection (mean, 54\%) against infection in cattle, and decreased the number of flukes developing to maturity and egg production (Dalton et al., 1996; Mulcahy et al., 1998).

However, recent work using $C$. elegans-expressed $H$. contortus CPL (Hc-CPL-1) as a vaccine in protection studies in sheep did not decrease egg development or hatching in immunised animals perhaps because the induced antibody did not adequately access the developing embryos (Murray et al., 2007). Localisation of Sv-
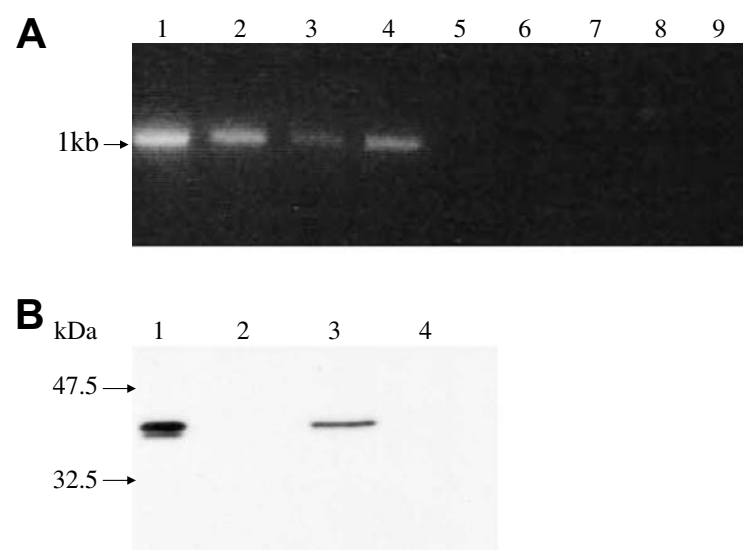

Fig. 4. (A) Single Worm PCR verified the presence of $S v-c p l-1$ in roller worms whereas non-roller and wild type (N2 strain) did not contain the $S v$-cpl-1 gene. Lanes 1-4, Sv-cpl-1 gene amplified with $S$. vulgaris gene specific primers SvF3 and SvR3, from single roller worms of established lines 1-4, respectively. Lanes 5-8, non-roller worms of established lines $1-4$, respectively, and Lane 9 , wild type worm amplified with SvF3 and SvR3. (B) Western blot analysis with anti-Ce-CPL-1 antibody on roller (lanes 1 and 3 ) and non-roller (lanes 2 and 4) worm extracts. CPL was expressed in rescued worms and not in non-transformed worms.
CPL- 1 would be necessary to determine if it is suitable as a vaccine target. Alternatively, this enzyme might be targeted using specific inhibitors of cathepsin $\mathrm{L}$, as some cysteine protease inhibitors are viable antiparasitics (Choe et al., 2005). The cysteine protease inhibitor $N$-Methyl-Pip-F-hF-VS $\Phi$ cured infection by Trypanosoma cruzi in immunodeficient mice (Doyle et al., 2007).

Novel anthelmintics with different modes of action and novel drug targets are now required due to the prevalence of anthelmintic resistance, especially in small strongyles. As these data suggest a conservation of cathepsin L-like gene function in Strongylida, a drug specifically inhibiting strongylid CPLs could generally serve if it inhibited embryogenesis thereby decreasing the incidence of and re-infection by the larva.

\section{Acknowledgments}

We thank the owner and staff of the Irish Abattoir Trading Co. Ltd., Straffan, Co. Kildare. The C. elegans wild type strain used in this work was provided by the Caenorhabditis Genetics Center, University of Minnesota, which is funded by the NIH National Center for Research Resources (NCRR). The authors also thank the $C$. elegans Gene Knockout Consortium (Oklahoma Medical Research Foundation) for the cpl-1 mutant.

\section{References}

Blaxter, M., De Ley, P., Garey, J.R., Liu, L.X., Scheldeman, P., Vierstraete, A. Vanfleteren, J.R., Mackey, L., Dorris, M., Firsse, L.M., Vida, J.T., Thomas, W.K., 1998. A molecular evolutionary framework for the phylum Nematoda. Nature 392, 71-75.

Breathnach, R., Chambon, P., 1981. Organization and expression of eukaryotic split genes coding for proteins. Annual Review of Biochemistry 50, 349-383.

Britton, C., Murray, L., 2002. A cathepsin L protease essential for Caenorhabditis elegans embryogenesis is functionally conserved in parasitic nematodes. Molecular and Biochemical Parasitology 122, 21-33.

Britton, C., Murray, L., 2004. Cathepsin L protease (CPL-1) is essential for yolk processing during embryogenesis in Caenorhabditis elegans. Journal of Cell Science 117, 5133-5143.

Brooks, D.R., Isaac, R.E., 2002. Functional genomics of parasitic worms: The dawn of a new era. Parasitology International 51, 319-325.

Caffrey, C.R., Ryan, M.F., 1994. Characterization of proteolytic activity of excretorysecretory products from adult Strongylus vulgaris. Veterinary Parasitology 52, 285-296.

Choe, Y., Brinen, L.S., Price, M.S., Engel, J.C., Lange, M., Grisostomi, C., Weston, S.G. Pallai, P.V., Cheng, H., Hardy, L.W., Hartsough, D.S., McMakin, M., Tilton, R.F., Baldino, C.M., Craik, C.S., 2005. Development of $\alpha$-keto-based inhibitors of cruzain, a cysteine protease implicated in Chagas' disease. Bioorganic and Medicinal Chemistry 13, 2141-2156.

Collins, P.R., Stack, C.M., O’Neill, S.M., Doyle, S., Ryan, T., Brennan, G.P., Mousley, A., Stewart, M., Maule, A.G., Dalton, J.P., Donnelly, S., 2004. Cathepsin L1, the major protease involved in Liver Fluke (Fasciola hepatica) virulence. Journal of Biological Chemistry 279, 17038-17046.

Dalton, J.P., McGonigle, S., Rolph, T.P., Andrews, S.J., 1996. Induction of protective immunity in cattle against infection with Fasciola hepatica by vaccination with cathepsin L proteinase and haemoglobin. Infection and Immunity 64, 50665074.

Dalton, J.P., O Neill, S., Stack, C., Collins, P., Walshe, A., Sekiya, M., Doyle, S., Mulcahy, G., Hoyle, D., Khaznadji, E., Moiré, N., Brennan, G., Mousley, A., Kreshchenko, N. Maule, A.G., Donnelly, S.M., 2003. Fasciola hepatica cathepsin L-like proteases: biology, function, and potential in the development of first generation liver fluke vaccines. International Journal for Parasitology 33, 1173-1181.

Day, S.R., Dalton, J.P., Clough, K.A., Leonardo, L., Tiu, W.U., Brindley, P.J., 1995. Characterization and cloning of the cathepsin L proteinases of Schistosoma japonicum. Biochemical and Biophysical Research Communications 217, 1-9.

Dowd, A.J., Tort, J., Roche, L., Dalton, J.P., 1997. Isolation of a cDNA encoding cathepsin L2 and functional expression in Saccharomyces cerevisiae. Molecular and Biochemical Parasitology 88, 163-174.

Doyle, P.S., Zhou, Y.M., Engel, J.C., McKerrow, J.H., 2007. A cysteine protease inhibitor cures Chagas' disease in an immunodeficient murine model of infection. Antimicrobial Agents and Chemotherapy 51, 3932-3939.

Emanuelsson, O., Nielsen, H., Brunak, S., von Heijne, G., 2000. Predicting subcellular localization of proteins based on their $\mathrm{N}$-terminal amino acid sequence. Journal of Molecular Biology 300, 1005-1016.

Epstein, H.F., Shakes, D.C., 1995. Caenorhabditis elegans: modern biological analysis of an organism. Methods in Cell Biology, vol. 48. Academic Press, San Diego, pp. $16-22$.

Guiliano, D.B., Hong, X., McKerrow, J.H., Blaxter, M., Oksov, Y., Liu, J., Ghedin, E., Lustigman, S., 2004. A gene family of cathepsin L-like proteases of filarial 
nematodes are associated with larval moulting and cuticle and eggshel remodelling. Molecular and Biochemical Parasitology 136, 227-242.

Harrison, P.M., Echols, N., Gerstein, M.B., 2001. Digging for dead genes: an analysis of the characteristics of the pseudogene population in the Caenorhabditis elegans genome. Nucleic Acids Research 29, 818-830.

Hashmi, S., Britton, C., Liu, J., Guiliano, D.B., Oksov, Y., Lustigman, S., 2002. Cathepsin $\mathrm{L}$ is essential for embryogenesis and development of Caenorhabditis elegans. Journal of Biological Chemistry 277, 3477-3486.

Hashmi, S., Zhang, J., Oksov, Y., Lustigman, S., 2004. The Caenorhabditis elegans cathepsin Z-like cysteine protease, $\mathrm{Ce}-\mathrm{CPZ}-1$, has a multifunctional role during the worms' development. Journal of Biological Chemistry 279, 6035-6045.

Holterman, M., Van der Wurff, A., Van den Elsen, S., Van Megan, H., Bongers, T. Holovachov, O., Bakker, J., Helder, J., 2006. Phylum-wide analysis of SSU rDNA reveals deep phylogenetic relationships among nematodes and accelerated evolution toward crown clades. Molecular Biology and Evolution 23, 1792 1800.

Ishidoh, K., Saido, T.C., Kawashima, S., Hirose, M., Watanabe, S., Sato, N., Kominami, E., 1998. Multiple processing of procathepsin L to cathepsin L in vivo. Biochemical and Biophysical Research Communications 252, 202-207.

Jasmer, D.P., Roth, J., Myler, P.J., 2001. Cathepsin B-like cysteine proteases and Caenorhabditis elegans homologues dominate gene products expressed in adult Haemonchus contortus intestine. Molecular and Biochemical Parasitology 116, 159-169.

Kaplan, R.A., 2002. Anthelmintic resistance in nematodes of horses. Veterinary Research 33, 491-507.

Larminie C.G.C. Johnstone, I. 1996. Isolation and characterization of four developmentally regulated cathepsin B-like cysteine protease genes from the nematode Caenorhabditis elegans. DNA and Cell Biology 15, 75-82.

Lustigman, S., Zhang, J., Liu, J., Oksov, Y., Hashmi, S., 2004. RNA interference targeting cathepsin L and Z-like cysteine proteases of Onchocerca volvulus confirmed their essential function during L3 moulting. Molecular and Biochemical Parasitology 138, 165-170.

McKerrow, J., 1999. Development of cysteine protease inhibitors as chemotherapy for parasitic diseases: insights on safety, target validation, and mechanism of action. International Journal for Parasitology 29, 833-837.

Mello, C.C., Kramer, J.M., Stinchcomb, D., Ambros, V., 1991. Efficient gene-transfer in C. elegans - extrachromosomal maintenance and integration of transforming sequences. The EMBO Journal 10, 3959-3970.

Ménard, R., Carmona, E., Takebe, S., Dufour, É., Plouffe, C., Mason, P., Mort, J.S., 1998 Autocatalytic processing of recombinant human procathepsin L. Journal of Biological Chemistry 272, 4478-4484.
Molento, M.B., Antunes, J., Bentes, R.N., Coles, G.C., 2008. Anthelmintic resistant nematodes in Brazilian horses. The Veterinary Record 162, 384-385.

Mounsey, A., Bauer, P., Hope, I.A., 2007. Evidence suggesting that a fifth of annotated Caenorhabditis elegans genes may be pseudogenes. Genome Research 12, 770775.

Mulcahy, G., O’Connor, F., McGonigle, S., Dowd, A.J., Clery, D., Andrews, S.J., Dalton, J.P., 1998. Correlation of specific antibody titre and avidity with protection in cattle immunized against Fasciola hepatica. Vaccine 16, 932-939.

Murray, L., Geldhof, P., Clark, D., Knox, D.P., Britton, C., 2007. Expression and purification of an active cysteine protease of Haemonchus contortus using Caenorhabditis elegans. International Journal for Parasitology 37, 1117-1125.

Neveu, C. Abad, P. Castagnone-Sereno, P. 2003. Molecular cloning and characterization of an intestinal cathepsin L protease from the plant-parasitic nematode Meloidogyne incognita. Physiological and Molecular Plant Pathology 63, 159-165.

Nielsen, H., Engelbrecht, J., Brunak, S., von Heijne, G., 1997. Identification of prokaryotic and eukaryotic signal peptides and prediction of their cleavage sites. Protein Engineering 10, 1-6.

Ray, C. McKerrow, J.H. 1992. Gut specific and developmental expression of a Caenorhabditis elegans cysteine protease gene. Molecular and Biochemical Parasitology 51, 239-250.

Sajid, M., McKerrow, J.H., 2002. Cysteine proteases of parasitic organisms. Molecular and Biochemical Parasitology 120, 1-21.

Shingles, J., Lilley, C.J., Atkinson, H.J., Urwin, P.E., 2007. Meloidogyne incognita: molecular and biochemical characterization of a cathepsin L cysteine proteinase and the effect on parasitism following RNAi. Experimental Parasitology 115 . 114-120.

Smith, A., Dowd, A.J., McGonigle, S., Keegan, P.S., Brennan, G., Trudgett, A., Dalton, J.P., 1993. Purification of a cathepsin L-like proteinase secreted by adult Fasciola hepatica. Molecular and Biochemical Parasitology 62, 1-8.

Swofford, D.L., 2002. PAUP : Phylogenetic Analysis Using Parsimony ( ${ }^{*}$ and other methods). Version 4, Sinauer Associates, Sunderland, MA (software program).

Tort, J., Brindley, P.J., Knox, D., Wolfe, K.H., Dalton, J.P., 1999. Proteinases and associated genes of parasitic helminths. Advances in Parasitology, vol. 43. Academic Press, San Diego, pp. 161-266.

Vernet, T., Berti, P.J., de Montigny, C., Musil, R., Tessier, D.C., Menard, R., Magny, M.C. Storer, A.C., Thomas, D.Y., 1995. Processing of the papain precursor. Journal of Biological Chemistry 270, 10838-10846.

Yamasaki, H., Mineki, R., Murayama, K., Ito, A., Aoki, T., 2002. Characterization and expression of the Fasciola gigantica cathepsin L gene. International Journal for Parasitology 32, 1031-1042. 